STUDI

FRANCESI

\section{Studi Francesi}

Rivista quadrimestrale fondata da Franco Simone

168 (LVI | III) | 2012

Varia

\title{
Correspondance et théâtre, textes réunis et présentés par Jean-Marc Hovasse
}

\section{Catherine Thomas}

\section{(2) OpenEdition \\ 1 Journals}

\section{Édition électronique}

URL : http://journals.openedition.org/studifrancesi/3758

DOI : 10.4000/studifrancesi.3758

ISSN : 2421-5856

Éditeur

Rosenberg \& Sellier

\section{Édition imprimée}

Date de publication : 1 décembre 2012

Pagination : $577-578$

ISSN : 0039-2944

\section{Référence électronique}

Catherine Thomas, "Correspondance et théâtre, textes réunis et présentés par Jean-Marc Hovasse »,

Studi Francesi [En ligne], 168 (LVI | III) | 2012, mis en ligne le 30 novembre 2015, consulté le 07 mars

2021. URL : http://journals.openedition.org/studifrancesi/3758 ; DOI : https://doi.org/10.4000/

studifrancesi.3758

Ce document a été généré automatiquement le 7 mars 2021.

\section{(c) 9 (i) $\Theta$}

Studi Francesi è distribuita con Licenza Creative Commons Attribuzione - Non commerciale - Non opere derivate 4.0 Internazionale. 


\title{
Correspondance et théâtre, textes réunis et présentés par Jean-Marc Hovasse
}

\author{
Catherine Thomas
}

\section{RÉFÉRENCE}

AA. VV., Correspondance et théâtre, textes réunis et présentés par Jean-Marc HOVASSE, Presses Universitaires de Rennes, 2012, «Interférences», pp. 310.

1 Cet ouvrage réunit les actes du colloque organisé par le Centre d'Étude des Correspondances et Journaux Intimes (UMR 6563 CNRS) en mars-avril 2011 à Brest. Dans la présentation, Jean-Marc HovASSE (pp. 9-18) souligne l'aspect novateur de l'étude des liens entre art dramatique et art épistolaire. Les multiples lettres et billets relatifs au monde du théâtre répertoriés dans les catalogues de marchands d'autographes, de nombreuses lettres extraites de correspondances générales, des épîtres liminaires ou des lettres écrites par des personnages dans des œuvres dramatiques, démontrent pourtant l'importance de ces relations.

2 Les deux articles de la première partie («Beaumarchais épistolier») éclairent la figure du dramaturge dans la correspondance de Beaumarchais. Bénédicte OBITZ (pp. 21-31) montre comment l'épistolier maîtrise la connaissance du monde littéraire de son temps et l'art de la rhétorique pour gérer au mieux les représentations de ses pièces, et défendre le statut d'auteur dramatique. Analysant la préface du Mariage de Figaro et les lettres que Beaumarchais adresse aux censeurs en 1784 et 1785 à propos de cette pièce, Marianne CHARRIER-VOZEL (pp. 32-43) insiste quant à elle sur la dimension dialogique et pragmatique de ces textes, faisant apparaître la façon dont ils tentent habilement de manipuler l'opinion publique, contre-pouvoir opposé à la censure, et d'imposer une certaine image de l'homme de lettre. 
3 La deuxième partie («Lettres et création») porte sur les échanges épistolaires qui eurent une incidence sur la pièce elle-même. Florence FILIPPI (pp. 47-61) s'intéresse à la lettre comme mémoire d'une collaboration active entre l'auteur et son interprète, à travers la correspondance entre Durcis et Talma. Ce dernier tint un rôle primordial dans l'écriture même du texte de théâtre: non seulement Durcis revoit et corrige sa pièce au fur et à mesure des représentations et des suggestions de l'acteur, mais il pense même le texte en fonction de ses audaces et de ses prouesses d'interprète. Dans Flaubert, Louis Bouilhet et le théâtre dans leur correspondance, Joëlle ROBERT (pp. 63-72) saisit chez Bouilhet «le lent processus de la création littéraire», dont Flaubert est simple témoin, ou participant actif par ses conseils, son regard critique. Ses attentes même sont génératrices d'écriture, car si la littérature est la "valeur suprême» pour Flaubert, c'est dans le désir de son destinataire que Bouilhet veut puiser la source de son inspiration. C'est encore l'aspect coopératif de l'art dramatique qui est mis à l'honneur dans l'article de Clélia ANFRAY (pp. 73-82): la correspondance entre Zola et Busnach, qui signa l'adaptation théâtrale de cinq romans zoliens, apparaît dans son étude comme un véritable «dialogue programmatique». Les lettres traduisent cependant un déséquilibre en faveur de Zola, qui multiplie critiques et consignes face à un Busnach effacé mais pourtant seul signataire des pièces ainsi créées. Marie-France DE PALACIO (pp. 83-123) s'intéresse aux lettres échangées entre Emile Bergerat et Camille de Sainte-Croix à propos du drame Manon Roland: cette correspondance fait apparaître «les années de démarches et de péripéties» qui précédèrent l'exécution de la pièce, sa réception contrastée, mais aussi les rivalités entre co-auteurs. Les deux articles suivants portent sur les relations entre l'auteur dramatique et ses actrices: la correspondance inédite de Dumas fils, analysée par Lise SABOURIN (pp. 125-143), nous renseigne sur les liens étroits, faits d'empathie et d'exigences, que le dramaturge tisse avec ses comédiennes; les lettres de Dumas précisent à la fois sa conception de l'art dramatique et sa vision de l'actrice, révélatrice du regard ambivalent qu'il porte sur la féminité. D'une tout autre nature, les lettres de Catulle Mendès à ses actrices favorites, étudiées par Jean DE PALACIO (pp. 149-160), mettent l'accent sur la dimension passionnelle que peut adopter ce type d'échange.

4 La troisième partie s'intitule «Pleins feux sur les correspondants». Elle s'ouvre par un article d'Olivier BARA (pp. 163-174), qui étudie les lettres de Marie Dorval à Alfred de Vigny. Ces lettres ne constituent pas seulement un précieux document sur la vie théâtrale en province $\mathrm{au} \mathrm{XIX}^{\mathrm{e}}$ siècle; textes à part entière, elles ont une valeur poétique et pragmatique. Elles traduisent la volonté de l'actrice de conserver l'amour de l'auteur, et sa propension à incarner son propre mythe; mais en narrant ses succès la comédienne vise surtout, de façon plus prosaïque, à assurer son retour sur les scènes parisiennes. Le public prend ainsi une place prépondérante dans les échanges épistolaires entre gens de théâtre, et si l'acteur souhaite susciter son désir, le dramaturge peut tenter de le manipuler pour favoriser le succès d'une pièce: étudiant une lettre de Marmontel au sujet d'Atys, Alexandre STROEV (pp. 175-184) met aussi en évidence la connaissance du métier de dramaturge que possède cet auteur, et la façon dont il utilise la presse pour influencer les spectateurs et la critique. Aline MARCHANDIER (pp. 185-200) restitue à Victorien Sardou son importance dans l'histoire littéraire en suivant, à travers sa correspondance, sa formation puis ses activités d'auteur à succès, la spécificité de son théâtre et sa volonté de tout maîtriser, du texte à la mise en scène, en un rêve de «dramaturge total». L'article suivant insiste sur la fonction formatrice 
que peuvent prendre les lettres à partir de l'exemple de Maeterlinck: Marianne BOUCHARDON (pp. 201-214) souligne comment la correspondance de l'écrivain, entre 1890 et 1893 , opère le passage «d'une conception livresque à une conception scénique de l'œuvre dramatique». La correspondance peut encore nous permettre de comprendre les coulisses et les enjeux tant politiques qu'esthétiques de pièces qui firent scandale dans le monde des Lettres, ainsi que le révèlent Pierre Jean DufIEF (pp. 215-226) à propos d'Henriette Maréchal des frères Goncourt, et Jeanne STRANART (pp. 227-236) au sujet de Ruy Blas et d'Hernani de Victor Hugo. Dans le cas d'Alain Fournier, la lettre est également révélatrice d'une personnalité et d'un imaginaire: lorsque l'écrivain évoque de grands dramaturges, ou l'écriture de sa propre pièce, apparaissent des thématiques et des traits stylistiques inhérents à l'ensemble de son œuvre, ainsi que l'expose Bernard-Marie GARREAU (pp. 237-251). Enfin Christophe C ORBIER (pp. 255-271) fait apparaître les conceptions esthétiques et dramaturgiques perceptibles dans la correspondance du musicien Maurice Emmanuel.

5 La quatrième partie met l'accent sur les lettres fictives et l'usage qui en est fait dans certaines pièces de théâtre. Soulignant l'importance de la lettre dans le théâtre de Marivaux, Eric FRANCALANZA (pp. 275-292) explore la richesse de ses significations. Non seulement la lettre permet de varier les effets scéniques et de préciser les répartitions sociales, mais elle contribue à la structuration même de l'intrigue, et peut prendre une dimension méta-dramatique. Véritable «instrument herméneutique», elle pourrait bien apparaître, dans le rapport complexe qu'elle entretient avec le désir, l'illusion, la vérité, comme le "genre emblématique» de ce théâtre. Tout aussi fondamental est le rôle de la correspondance dans le théâtre de Cocteau: selon Serge LinARÈs (pp. 293-303) elle «donne corps à un imaginaire qui transcende sa réalité tangible». Elle dit le mystère de l'inspiration, les aléas de la réception poétique, les difficultés d'une communication altérée par une modernité fatale, mais aussi le traumatisme que fut, pour Cocteau enfant, l'absence d'un père qui ne laissa, lors de son départ, aucune lettre.

6 Par la variété des perspectives qu'il aborde, qu'elles soient de nature historique, esthétique, sociologique ou biographique, cet ouvrage atteste de l'importance fondamentale des correspondances dans la connaissance de l'histoire du théâtre et des auteurs qui l'ont constituée. 